\title{
Within-Species Trait Variation Can Lead to Size Limitations in Seed Dispersal of Small-Fruited Plants
}

\author{
Finn Rehling ${ }^{*}$, Bogdan Jaroszewicz' ${ }^{2}$, Leonie Victoria Braasch ${ }^{1}$, Jörg Albrecht ${ }^{3}$, \\ Pedro Jordano ${ }^{4}$, Jan Schlautmann', Nina Farwig' and Dana G. Schabo ${ }^{1}$ \\ ${ }^{1}$ Conservation Ecology, Department of Biology, Philipps-University Marburg, Marburg, Germany, ${ }^{2}$ Białowieża Geobotanical \\ Station, Faculty of Biology, University of Warsaw, Warsaw, Poland, ${ }^{3}$ Senckenberg Biodiversity and Climate Research Centre \\ Frankfurt, Frankfurt, Germany, ${ }^{4}$ Integrative Ecology Group, Estación Biológica de Doñana, CSIC and University of Sevilla, \\ Seville, Spain
}

The inability of small-gaped animals to consume very large fruits may limit seed dispersal of the respective plants. This has often been shown for large-fruited plant species that remain poorly dispersed when large-gaped animal species are lost due to anthropogenic

OPEN ACCESS

Edited by:

Evan Fricke,

Rice University, United States

Reviewed by:

Diane Lynn Larson,

United States Geological Survey

(USGS), United States

Mariano Ordano,

Fundación Miguel Lillo, Argentina

*Correspondence:

Finn Rehling

rehling@uni-marburg.de

Specialty section:

This article was submitted to

Population, Community,

and Ecosystem Dynamics,

a section of the journal

Frontiers in Ecology and Evolution

Received: 22 April 2021

Accepted: 20 July 2021

Published: 16 August 2021

Citation:

Rehling $F$, Jaroszewicz $B$,

Braasch LV, Albrecht J, Jordano P,

Schlautmann J, Farwig $N$ and Schabo DG (2021) Within-Species

Trait Variation Can Lead to Size

Limitations in Seed Dispersal

of Small-Fruited Plants.

Front. Ecol. Evol. 9:698885.

doi: 10.3389/fevo.2021.698885 pressure. Little is known about whether gape-size limitations similarly influence seed dispersal of small-fruited plant species that can show a large variation in fruit size within species. In this study, fruit sizes of 15 plant species were compared with the gape sizes of their 41 animal dispersers in the temperate, old-growth Białowieża Forest, Poland. The effect of gape-size limitations on fruit consumption was assessed at the plant species level, and for a subset of nine plant species, also at the individual level, and subindividual level (i.e., fruits of the same plant individual). In addition, for the species subset, fruit-seed trait relationships were investigated to determine whether a restricted access of small-gaped animals to large fruits results in the dispersal of fewer or smaller seeds per fruit. Fruit sizes widely varied among plant species $(74.2 \%)$, considerably at the subindividual level (17.1\%), and to the smallest extent among plant individuals (8.7\%). Key disperser species should be able to consume fruits of all plant species and all individuals (except those of the largest-fruited plant species), even if they are able to consume only $28-55 \%$ of available fruits. Fruit and seed traits were positively correlated in eight out of nine plant species, indicating that gape size limitations will result in $49 \%$ fewer (in one) or 16-21\% smaller seeds (in three plant species) dispersed per fruit by small-gaped than by large-gaped main dispersers, respectively. Our results show that a large subindividual variation in fruit size is characteristic for small-fruited plant species, and increases their connectedness with frugivores at the level of plants species and individuals. Simultaneously, however, the large variation in fruit size leads to gape-size limitations that may induce selective pressures on fruit size if large-gaped dispersers become extinct. This study emphasizes the mechanisms by which gape-size limitation at the species, individual and subindividual level shape plant-frugivore interactions and the co-evolution of small-fruited plants.

Keywords: gape-size limitation, phenotypic variation, seed mass and number, seed dispersal mutualism, trait matching, fruit selection, frugivores, intraindividual variability (IIV) 


\section{INTRODUCTION}

The fleshy fruits of plants are an important food source for many animals (Snow and Snow, 1988; Jordano, 2014; Albrecht et al., 2018b; Quintero et al., 2020; González-Varo et al., 2021). In exchange for the provided pulp, animals disperse the seeds of the fruits, which is critical to the recruitment of plant populations (Howe and Smallwood, 1982). Seed dispersal is typically carried out by multiple species of animals; conversely, those animals feed on the fruits of multiple species of plants (Zamora, 2000; Blüthgen et al., 2007). Nevertheless, the morphological, physiological, and behavioral traits of plants and animals have co-evolved such that certain plant-animal interactions are favored over others (Gautier-Hion et al., 1985; Jordano, 1987; Albrecht et al., 2015, 2018b).

Co-evolved traits include the sizes of the fruits and the gapes of their animal dispersers (Moermond and Denslow, 1985; Wheelwright, 1985; Jordano, 1995a; Eklöf et al., 2013; Albrecht et al., 2018a,b; Schleuning et al., 2020). Because animals can poorly feed on fruits that are larger than their gape (Levey, 1987; Rey et al., 1997), the diversity of dispersing animals decreases with increasing fruit size, such that large-fruited plant species are dispersed only by a few large-gaped animals (Janzen and Martin, 1982; Guimarães et al., 2008). The reliance of a plant species on large-gaped animals for seed dispersal may result in strong population declines, once their main dispersers become functionally lost. This has been observed especially in the tropics (e.g., Galetti et al., 2013; Kurten, 2013; Correa et al., 2015; Lim et al., 2020) and on islands (e.g., Pérez-Méndez et al., 2016; Brodie, 2017; Case and Tarwater, 2020), where, following anthropogenic pressure, the inability of simplified, downsized animal communities to consume large fruits limits the regeneration of the respective plants (Terborgh et al., 2008; Brodie et al., 2009). Despite these strong examples, the diameters of the vast majority of fruits and gapes are $<1.2 \mathrm{~cm}$ (Wheelwright, 1985; Wenny et al., 2016), and the extent to which gape-size limitations determine the interactions between small-fruited plants and small-gaped seed dispersers is unclear.

Within-species levels of trait variation may lead to gapesize limitations that do not take place at the species level (as observed in the large-fruited plant species), but subtler at the individual or subindividual level. Fruits of plants can vary in their size among different plant individuals (interindividual variation) due to genetic differences, differences in plant size or the environment (Foster, 1990; Wheelwright, 1993; GonzálezVaro and Traveset, 2016). Simultaneously, fruit size also varies within individuals (subindividual variation), because flowers receive a different amount of pollen during pollination, or fruits differ in their vertical position, or light conditions (Jackson and Sharples, 1971; Lloyd, 1984; Dogterom et al., 2000; Herrera, 2009, 2017). Thus, for example, in the common myrtle Myrtus communis, while all of its main dispersers are able to feed on its fruits, the actual disperser assemblage differs between plant individuals bearing fruits of different sizes, such that some individuals have potentially only two and others up to five main dispersers (González-Varo and Traveset, 2016). In the olive tree Olea europaea, the large fruits of cultivated plants can be consumed by only one disperser whereas the small fruits of wild individuals are consumed by all four main dispersers (Rey et al., 1997). On top of the variation in plants, substantial interindividual variation occurs in the gape width of seeddispersing animals, due either to ontogenetic differences or due to sexual dimorphism (González-Varo and Traveset, 2016; Zwolak, 2018).

The resulting community-wide trait variation in fruit and gape sizes not only determine the interactions among plants and animals at different ecological levels (species, individual, subindividual level), they may also play a role in the success and effectiveness of seed dispersal (Schupp et al., 2010). Within plant species, fruit size was shown to positively correlate with the number or mass of dispersed seeds per fruit (e.g., Sallabanks, 1993; Alcántara and Rey, 2003; Hernández, 2009). Seed size, in turn, mediates other dispersal-related processes, such as the dispersal ability of seeds, the seed's susceptibility to natural enemies, and the performance of the seedlings after germination (Leishman et al., 2000; Muller-Landau, 2010; Fricke et al., 2019). If the animal's gape size constrains its fruit choice, then large-gaped animals will be able to disperse more or larger seeds per fruit than small-gaped animals, because they are able to consume larger fruits (Alcántara and Rey, 2003; Hernández, 2009; Herrera, 2009; Galetti et al., 2013; González-Varo et al., 2014; Carvalho et al., 2021). Thus, the within-species trait variation in fruit size could potentially have direct and indirect consequences for both the quantity and the quality of seed dispersal, even in plant species with small fruits.

In this study, we describe the extent to which gape-size limitations structure species interactions between small-fruited plants and their associated frugivores, and how gape-size limitations influence the mass or number of dispersed seeds by small-gaped frugivores. We combined data on fruit removal (Albrecht et al., 2013), seed deposition (Schlautmann et al., 2021), fruit and seed traits, and gape widths (Herrera, 1984; Jordano, 1984a) of a diverse plant-frugivore community of the lowland temperate forests in Białowieża Forest (Eastern Poland). First, we characterized the community-wide trait variation in both the fruit diameter of plants and the gape widths of seed dispersers at the species level. In addition, we characterized the within-species trait variation for a subset of nine plant species and their six main dispersers. Second, we tested and quantified to which extent the different levels of trait variation of fruit diameter and gape width affect the interactions between plants and their seed dispersers at the species level (all species) and within species at the individual and subindividual level (subset only). For the species subset, we further tested, third, if fruit size is positively related to the key determinants of post-dispersal seedling establishment, i.e., the number and mean mass of seeds per fruit. Finally, we described the consequences of gape-size limitations for seed dispersal by testing whether fruit diameter and gape width affected the number and mass of dispersed seeds. 


\section{MATERIALS AND METHODS}

\section{Study Area and Species}

The study was conducted in the Białowieża Forest, which covers an area of 1,506 $\mathrm{km}^{2}$ and spans the borders of Poland and Belarus. The Polish part of the forest $\left(\sim 625 \mathrm{~km}^{2}\right)$ is divided into the Białowieża National Park $\left(\sim 105 \mathrm{~km}^{2}\right)$ and state forests. The $48-\mathrm{km}^{2}$ Białowieża National Park has been continuously protected for almost 500 years, first as a royal hunting ground and since 1921 strictly as a national park. It is therefore the best-preserved lowland forest in Europe (Samojlik et al., 2019; Jaroszewicz et al., 2019). By contrast, commercial logging has been allowed in $>80 \%$ of Polish state forests since the First World War (Mikusiński et al., 2018; Jaroszewicz et al., 2019).

Up to $20 \%$ of the Białowieża Forest is dominated by alder (Jaroszewicz et al., 2019), and is home to a diverse community of at least 15 woody, fleshy-fruited plant species (Supplementary Table 1, see also Albrecht et al., 2015). For the study of within-species trait variation and fruit-seed trait relationships of small-fruited plant species, we focused on the nine most abundant plant species in the middle layer and understory of the forest: Euonymus europaeus (European spindle), Frangula alnus (alder buckthorn), Prunus padus (bird cherry), Rhamnus cathartica (European buckthorn), Ribes nigrum (black currant), Ribes spicatum (downy currant), Sambucus nigra (elder), Sorbus aucuparia (rowan), and Viburnum opulus (guelder rose). These species belong to five plant families and are either trees $(n=6$ species) or shrubs $(n=3)$. They produce red $(n=4)$ or black $(n=5)$ fruits and their fruiting season starts in June (P. padus and $R$. spicatum) and ends in October (E. europaeus). The seeds of these plants are dispersed by many different animal species (Supplementary Table 2), including at least 10 mammalian and 31 avian frugivores (Albrecht et al., 2013; Jaroszewicz et al., 2013; Schlautmann et al., 2021). However, the contribution of these species to the total seed dispersal of the plant community in the Białowieża Forest is highly heterogeneous, as only five bird species, i.e., Erithacus rubecula (European robin), Sylvia atricapilla (Eurasian blackcap), S. borin (garden warbler), Turdus merula (common blackbird), T. philomelos (song thrush) and one mammal, the European pine marten Martes martes, account for $97.0 \%$ of the fruit removal interactions and $98.6 \%$ of the seed rain (Schlautmann et al., 2021). In the following, these six species are referred to as the main seed dispersers in the studied community.

\section{Fruit and Seed Traits of Plants at the Species, Individual and Subindividual Levels}

To describe the community-wide trait variation in fruit diameter of small-fruited plants, we collected data for 15 woody, fleshyfruited plant species at the species level, and for a subset of nine plant species also at the individual and subindividual levels. The data on the fruit diameters at species level were based on the fruit measurements performed in this study (see next section) and on the measurements reported in Albrecht et al. (2018b) for the remaining six plant species (Supplementary Table 1). For Rubus ideaus (raspberry), a fruit-size diameter of $0.34 \mathrm{~cm}$
(Robbins and Moore, 1991) was assumed because animals feed on single drupelets of the polydrupe.

For the subset of nine plant species, fruit samples from (7-)1215 individual adult plants per species (mean \pm SD: $12.8 \pm 2.5$ ) were collected in the Białowieża Forest, for a total of 115 adult plant individuals (Supplementary Table 1). Ripe fruits were sampled between June and September 2018, aligned with the fruiting phenologies of the species. The collected fruits were stored in a freezer at $-4^{\circ} \mathrm{C}$. Between 4 and 22 fruits per plant individual $(8.8 \pm 2.8)$ were depulped for use in the analysis, resulting in 99-151 fruits per plant species (112.4 \pm 22.0 , Supplementary Table 1). The diameters of the frozen fruits were recorded to the nearest $0.01 \mathrm{~cm}$ (mean length and width of the fruit; referred to hereafter as fruit diameter). Intact seeds were extracted and then dried at room temperature for 2 days. The number of seeds per fruit and the mean dry mass of the seeds per fruit, defined as the total mass of seeds divided by the number of seeds per fruit, were determined. Fruits of $R$. cathartica often contained aborted seeds (mass $<7 \mathrm{mg}$ ) that seldom germinated (data not shown). Those seeds were excluded from estimates of the number and mass of seeds per fruit. In addition, because some fruits of $S$. aucuparia were infested by larvae of Argyresthia conjugella and seed-dispersing species tend to avoid eating infested fruits (Manzur and Courtney, 1984), only the non-infested fruits of S. aucuparia were considered.

\section{Gape Width of Animals at the Species and Individual Levels}

Data from three sources (Herrera, 1984; Jordano, 1984a, specimen collection, unpublished) were used to determine the gape width for 30 of the 41 studied disperser species from the Białowieża Forest at the species level. Herrera (1984) and Jordano (1984a) measured the gape width of mist-netted birds from Southern Spain (1978-1982) and Northern Spain (1980-1983), respectively. In the Appendix of the report by Herrera (1984), only the mean values were listed whereas in the dataset provided by Jordano (1984a) the gape widths of up to 20 individuals per bird species were recorded. Because gape widths can differ between animals of different populations and depending on the observer (see Supplement of González-Varo and Traveset, 2016), in this study the mean values of Herrera (1984) and Jordano (1984a) were averaged when data from both sources were available. In the absence of information on the gape width of living individuals, the values were based on measurements of up to four mounted specimens within the animal collection of Philipps-Universität Marburg (Supplementary Table 2). However, the gape of mounted animals is stiff, such that the mean gape width was consistently smaller $(F=14.08, p<0.001)$ than reported by Herrera (1984) and Jordano (1984a). In all three data sources, the gape width of birds was measured at the internal commissures of the mouth using a caliper and recorded to the closest $0.01 \mathrm{~cm}$. For Carpodacus erythrinus (common rosefinch), no data were available and the gape width was therefore predicted based on bird species with a similar body mass and diet as reported by Herrera (1984) (Supplementary Figure 1). For mammalian dispersers, information on gape width was rare and 
all mammalian species $(n=10)$ were therefore expected to have a gape width of $\geq 2 \mathrm{~cm}$.

Because the gape width of bird species was averaged from measurements reported in different studies, interindividual differences in the gape width of the main dispersers were simulated by sampling 50 individuals with the speciesspecific mean gape width and the variation of gape width reported by Jordano (1984a), SD in E. rubecula $=0.036 \mathrm{~cm}$, S. atricapilla $=0.033 \mathrm{~cm}$, S. borin $=0.037 \mathrm{~cm}$, T. philomelos $=0.037 \mathrm{~cm}, T$. merula $=0.101 \mathrm{~cm}$. Smallgaped, intermediate-gaped, and large-gaped individuals within species were defined accordingly, based on the $10 \%$ quantile, the mean, and the $90 \%$ quantile of the gape width of simulated individuals (Supplementary Table 3).

\section{Statistical Analyses \\ Trait Variation in Fruit Diameter and Gape Width at the Species, Individual and Subindividual Level}

We summarized the community-wide trait variation in the fruit diameter of plants and the gape width of frugivores at the species level (Figure 1). Frugivores were defined as all animal species recorded eating fruits of any of the studied plant species at least once, either during fruit removal observations in 2011/2012 (Albrecht et al., 2013) or based on the seeds found in the scat of animals collected in 2016-2018 (Schlautmann et al., 2021). Because we did not have direct measures of the gape widths of mammals, a cut-off was set at $2 \mathrm{~cm}$. The black woodpecker Dryocopus martius (the only bird with a gape size $>2 \mathrm{~cm}$ ) was grouped with mammals, thus yielding a group of large-gaped animals whose choice of fruits was not limited by gape width (Figure 1 and Supplementary Tables 1, 2).

We tested if the gape width of seed disperser species was related to the maximum and mean diameters of the consumed fruits at the species level. The maximum diameter of the consumed fruits was defined as the mean fruit diameter of the largest-fruited plant species fed upon by a given seed disperser species, based either on observations of fruit removal (Albrecht et al., 2013) or on seed deposition (Schlautmann et al., 2021). The mean diameter of fruits removed by a given seed disperser species was calculated by weighting the fruit diameter of each plant species by the disperser-specific fruit consumption rate. The mean fruit diameter was determined solely on the basis of fruit-removal observations (Albrecht et al., 2013), not on seed depositions, because the mean fruit consumption rate cannot be adequately calculated from the number of seeds in scats. This is because birds usually deposit only a few seeds at most (not all seeds of one or more fruits) at the same place, and this behavior might depend on the plant species. Similarly, the number of seeds in scats might have been confounded by within-species differences in fruit choice among animal species. The effect of gape width on an animal's choice of fruits at the species level was evaluated using linear models in which the maximum and mean diameters of the fruits removed by each seed disperser species served as the response variable and the gape width of the respective seed disperser species as the continuous explanatory variable. In the analyses of maximum and mean fruit diameters, mammals were not included due to the missing values for gape width $(n=4)$. The nine avian seed disperser species that were observed less than six times were also excluded because the sample size was too low to consider their fruit choices as representative. Thus, the maximum and mean diameters of consumed fruits were analyzed for 17 seed disperser species. To test if the number of disperser species of a plant species decreases with the increasing diameter of fruits at the species level, generalized linear effect models were used with the number of disperser species as the response variable and fruit diameter as the fixed explanatory variable. The models included a logit link and a Poisson error distribution (analysis of deviance, Quinn and Keough, 2002).

For a subset of the nine most abundant plant species and their six main dispersers (see "Study area and species"), we quantified the extent to which gape-size limitations could potentially affect fruit removal and fruit consumption within species. To do so, we calculated the proportion of fruits from each plant species that could be swallowed (i.e., falling within the size interval of the gape widths) by the six main seed disperser species (proportion of accessible fruits for consumption, i.e., animal perspective; or proportion of fruits that can be dispersed by different animals, respectively, i.e., plant perspective; see Supplementary Table 3). In addition, we quantitatively compared the different levels of trait variation in fruit diameter of the nine plant species. The coefficient of variation $(\mathrm{CV})$, defined as the sample variability (standard deviation) divided by the mean of the sample, and variance partitioning were used to compare the levels of trait variation in fruit diameter and the mean seed mass in plants among species, among individuals, and within individuals (subindividual). The CV was chosen because it provides a measure of trait variability from the individual perspective and is thus wellsuited for comparisons of individuals within species. As a second measure, we used variance partitioning as it is able to provide a measure of trait variability from the community perspective and was thus well-suited for comparing the variability within and among species. In this study, it was used to separate the total community variability in fruit diameter and mean seed mass per fruit into the underlying contributions of species, individual, and subindividual variation. As both the $\mathrm{CV}$ and variance partitioning have different mathematical drawbacks and describe different aspects of trait variation, they were used in combination (Herrera, 2009). The variance component (VC) models were fitted using an ANOVA-type (type I sums of squares) estimation for unbalanced mixed models, with the fruits nested in plant individuals nested in plant species as random factors (Searle et al., 1992). Significant differences between factors were based on 95\% confidence intervals (95\%CIs) using Satterthwaite's correction. Differences in the subindividual variation in fruit diameter between plant species were tested using the subindividual $\mathrm{CV}$ of individuals as replicates and by constructing linear models with plant species as the fixed factor. A potential relationship between the individual and subindividual CVs among plant species was investigated by averaging the subindividual $\mathrm{CV}$ per species and using a Spearman correlation. 


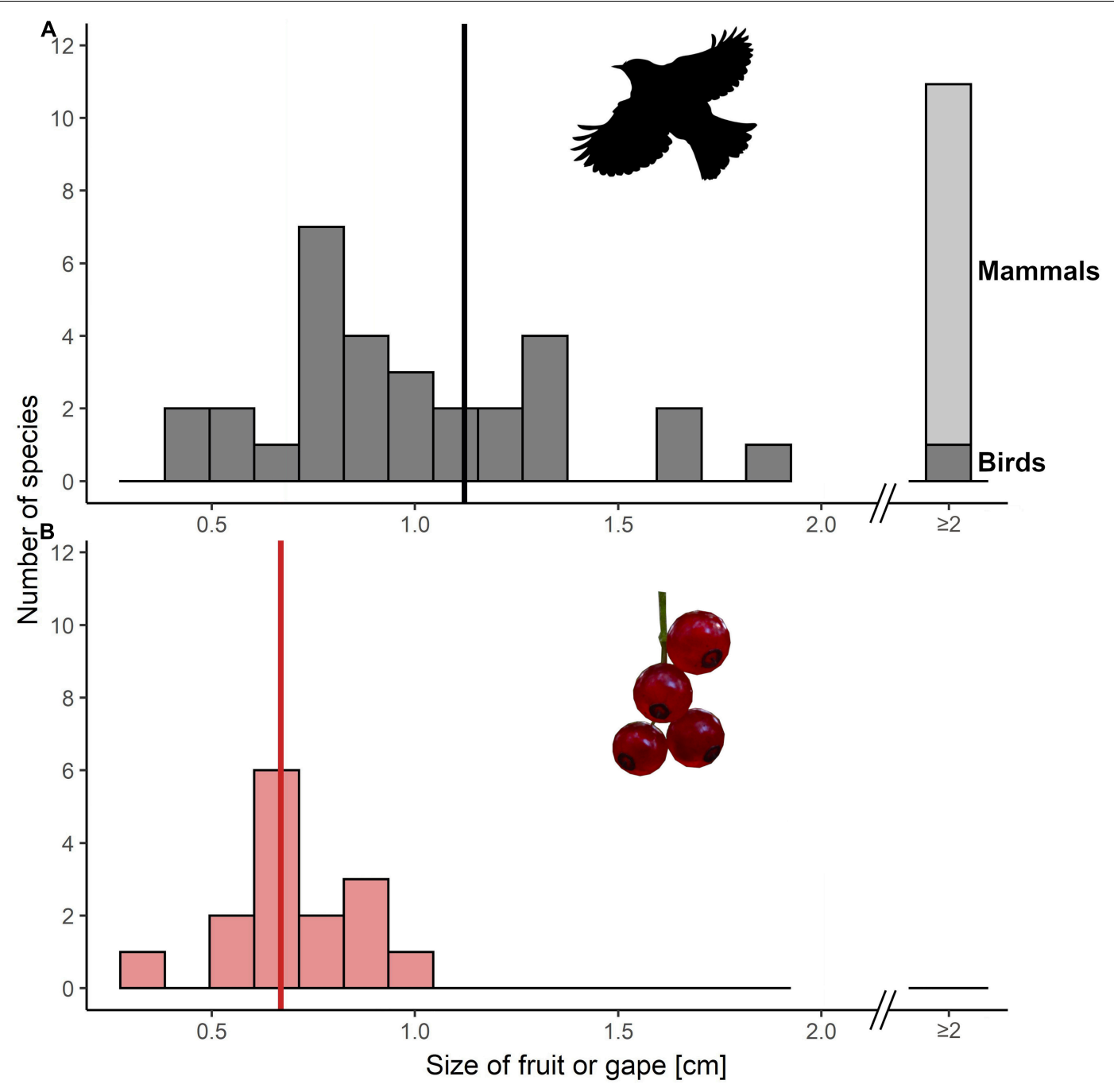

FIGURE 1 | Distribution of (A) the gape widths of animal dispersers and (B) the fruit diameter of associated plants at species level in temperate forests in Białowieża Forest, Poland. This is a summary of the local plant-frugivore community, whose contributing species were identified either based on fruit removal observations (Albrecht et al., 2013) or based on seeds in scats of animals (Schlautmann et al., 2021). Vertical lines illustrate the median value of a distribution.

\section{Fruit-Seed Trait Relationships}

For the subset of the nine most abundant plant species, the relationship between fruit diameter and the seed traits of the plant species was assessed using (generalized) linear mixed models. In these models, the number or the mean mass of seeds per fruit served as the response variable, the fruit diameter, plant species and their interaction as the continuous explanatory variables, and the individual plant (from which the fruits had been collected) as a random factor. However, these models performed poorly which may have been due to the following reasons: first, the number of seeds per fruit was morphologically constrained in five of the nine plant species (E. europaeus, F. alnus, P. padus, $S$. nigra, and V. opulus) and hardly varied among fruits. Second, a linear mixed model with a normal error distribution performed best in the analyses of the number of seeds of $R$. cathartica and $S$. aucuparia, but a Poisson error distribution performed better in the models of $R$. nigrum and $R$. spicatum. Third, the number of seeds, the mean seed mass, and fruit size strongly differed between plant species, and the absence of overlap in the ranges of the values of the different plant species cast doubt on the accuracy of the model outcome. Thus, each of the nine plant species was tested separately and the probability values for multiple comparisons were adjusted using a Bonferroni correction to avoid a type I error.

\section{Consequences of Gape-Size Limitations for Dispersed Seeds}

For the subset of the nine most abundant plant species and the six main dispersers, a possible effect of the gape width of the seed disperser species on the number or mean mass of seeds per fruit was analyzed. The number or mean mass of seeds per fruit was bootstrapped by randomly sampling 50 fruits of the studied plant species with 1,000 replacements. For each of the bootstrap replicates, the maximum fruit diameter that could be 
sampled was limited according to the gape width of the animal species or individual. Pairwise mean value comparisons of the bootstrapped data were performed to test whether differences in the gape width of seed disperser species was the sole explanation for the differences in the number or mass of dispersed seeds, i.e., the probability that the mean value of the dispersed seeds of small-gaped seed dispersers was larger than that of largegaped seed dispersers (based on one-tailed $p$-values). This was achieved by grouping the large-gaped main seed disperser species (M. martes, T. merula, T. philomelos), because they were not limited in their fruit choices, and adjusting the probability values for multiple comparisons between the main seed disperser species using a Bonferroni correction, to avoid a type I error. Because the results were slightly variable among iterations (i.e., random seeds), we present the mean effect sizes and mean probability values of 50 iterations of the pairwise mean value comparisons of the bootstrapped data.

All statistical analyses were conducted using the $\mathrm{R}$ program version 4.0.3 ( $\mathrm{R}$ Core Team, 2020). Variance component analyses were performed using the R-package VCA version 1.4.3 (Schuetzenmeister and Dufey, 2020). Generalized linear mixed models were constructed using the package lme4 version 1.1-23 (Bates et al., 2015). Significance values for the effect of fixed factors were obtained using Wald- $\chi^{2}$-tests (type II sums of squares) in the package car version 3.0-9 (Fox and Weisberg, 2019).

\section{RESULTS}

\section{Trait Variation in Fruit Diameter and Gape Width at the Species, Individual and Subindividual Level}

In Białowieża Forest, 15 fleshy-fruited plant species are dispersed by 41 animal species (10 mammal and 31 bird species, Figure 1; Albrecht et al., 2013; Schlautmann et al., 2021). At the species level, the mean fruit diameter ranged from $0.51 \mathrm{~cm}$ in $S$. nigra to $0.96 \mathrm{~cm}$ in $V$. opulus and was therefore smaller (median $=0.67 \mathrm{~cm}$ ) than the gape width of the associated seed disperser assemblage $($ median $=1.12 \mathrm{~cm})$.

From the community perspective, trait variation in fruit diameter was largely explained by differences among plant species $\left(\mathrm{VC}_{\text {species }}=1.87,95 \% \mathrm{CI}: 0.84-6.99\right)$. However, more of the total variation in the fruit diameter within a plant species was explained by the subindividual than by the interindividual variation $\left(\mathrm{VC}_{\text {subindividual }}=0.43\right.$, 95\%CI: $0.39-$ 0.47 and $\mathrm{VC}_{\text {individual }}=0.22,95 \% \mathrm{CI}: 0.16-0.31$, respectively, Table 1). The subindividual variation in fruit diameter differed significantly between plant species $\left[F_{(8,106)}=11.8, p<0.001\right]$ and was smallest in V. opulus and largest in R. spicatum (Figure 2 and Supplementary Figure 2). The interindividual and subindividual variation in fruit diameter were not significantly rank-correlated across species $(n=9$, Spearman's $\rho=0.45, p=0.230)$.

The gape width of seed dispersers also varied considerably among species (Figure 1) and among individuals of the same species (Figure 2). When the community-wide trait variation in
TABLE 1 | Analyses of variance components of fruit diameter and mean seed mass per fruit across nine fleshy-fruited plant species in Białowieża Forest, Poland.

\begin{tabular}{lcccc}
\hline & VC & \% Var & CV [\%] \\
\hline \multicolumn{4}{c}{ Fruit diameter } \\
\hline Community & 2.51 & 100.00 & 22.16 & \\
Species & 1.87 & 74.17 & 19.08 & $\mathrm{a}$ \\
Individual & 0.22 & 8.71 & 6.54 & $\mathrm{c}$ \\
Subindividual & 0.43 & 17.11 & 9.16 & $\mathrm{~b}$ \\
\hline & & Mean seed mass & & \\
\hline Community & 833.53 & 100.00 & 103.76 & \\
Species & 765.50 & 91.84 & 99.44 & $\mathrm{a}$ \\
Individual & 31.30 & 3.76 & 20.11 & $\mathrm{~b}$ \\
Subindividual & 36.74 & 4.41 & 21.78 & $\mathrm{~b}$ \\
\hline
\end{tabular}

VC, ANOVA-type estimation of variance components (Searle et al., 1992).

$\%$ Var, Proportion of total community-level variance in plant traits explained by different ecological scales: variation among species (species), variation among individuals of the same species (individual), variation within individuals of the same species (subindividual).

CV [\%], Coefficient of variation of different ecological scales.

Lower cases $(a, b, c)$ indicate significant differences between VC, \%Var and CV [\%] of the different ecological scales based on 95\% confidence levels using "Satterthwaite" approach (Schuetzenmeister and Dufey, 2020).

gape width and fruit diameter was considered, all plant species produced fruits small enough to be swallowed by all of the main seed dispersers in the studied plant-frugivore community (E. rubecula, M. martes, S. atricapilla, S. borin, T. merula, T. philomelos). In five of the nine studied plant species, the main seed disperser could potentially feed on $>90 \%$ of the total available fruits (based on the mean gape width of seed disperser species, Figures 2, 3 and Supplementary Table 3). In three plant species (F. alnus, R. nigrum, S. aucuparia), the main smallgaped seed dispersers (E. rubecula, S. atricapilla, S. borin) could feed only on $28-55 \%$ of the available fruits, but could interact with most individuals in the population (66-100\%, based on the mean gape width of the studied species, Figure 3). The fruits of $V$. opulus seemed to be barely accessible to small-gaped main dispersers (E. rubecula, S. atricapilla, S. borin) whereas the three main large-gaped seed dispersers (M. martes, T. philomelos, and $T$. merula) were potentially not size-limited in their fruit choices, neither among nor within plant species (Figures 1-3 and Supplementary Table 3 ).

Fruit size did not affect the number of seed disperser species feeding on the fruits $\left(\chi^{2}=0.07, p=0.794\right.$, Figure 4A). However, the maximum $\left[F_{(1,15)}=4.69, p=0.047\right]$ and mean $\left[F_{(1,15)}=5.50\right.$, $p=0.033$ ] diameters of the consumed fruits increased with the increasing gape width of the seed disperser species (Figure 4B). Only in $16.4 \%$ of the interactions did seed dispersers consume the fruits of plant species that were on average larger than their mean gape width (Figure $4 B$ ).

\section{Fruit-Seed Trait Relationships}

The number of seeds per fruit was biologically constrained in five of the nine studied plant species (1-3 seeds per fruit). For example, $P$. padus and V. opulus have drupaceous fruits, always 


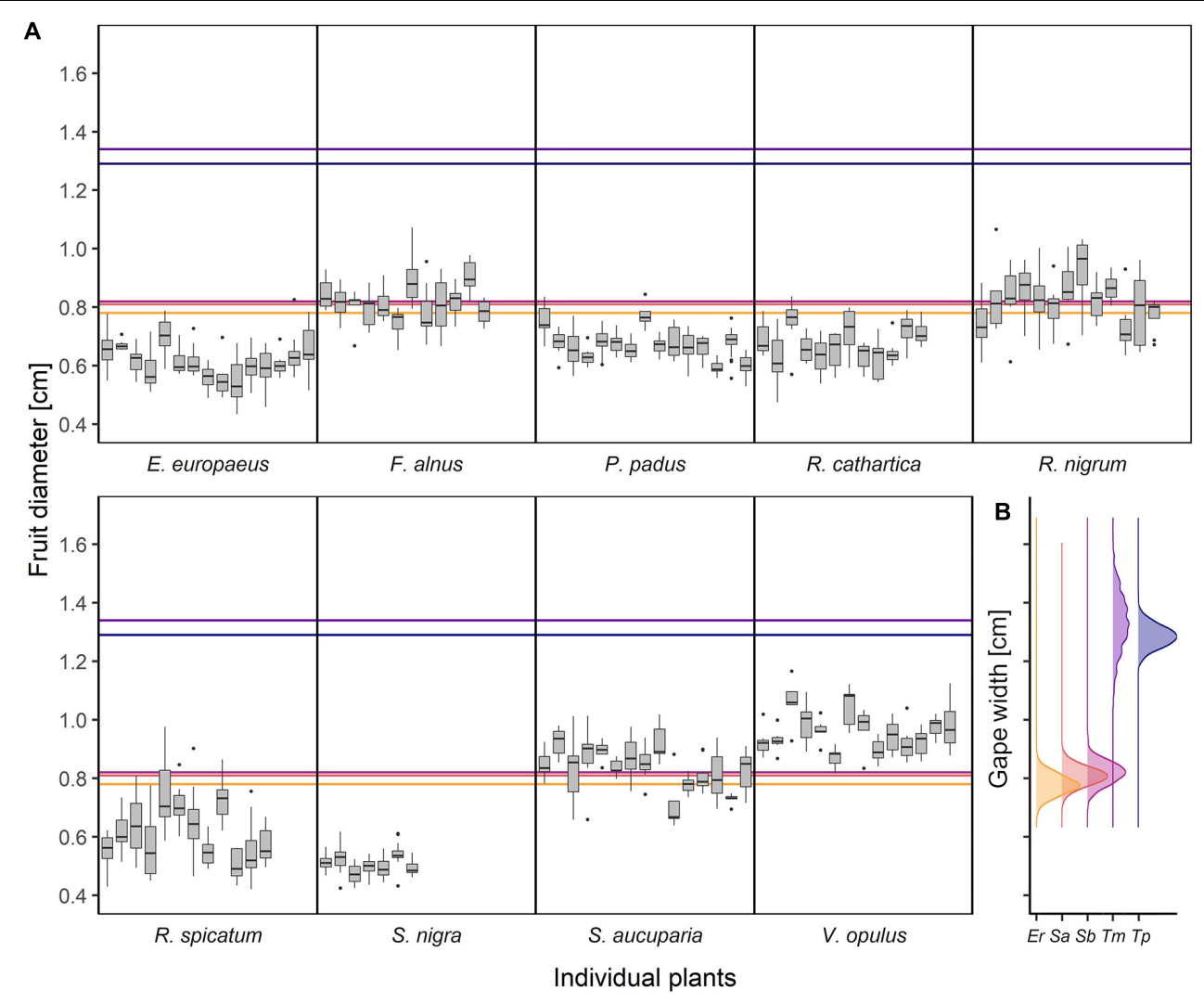

FIGURE 2 | (A) Boxplots showing sub- and interindividual variation in fruit diameter across nine fleshy-fruited plant species in Białowieża Forest, Poland. (B) Density plot of gape width of the five most important frugivore species (Er, Erithacus rubecula; Sa, Sylvia atricapilla; Sb, Sylvia borin; Tm, Turdus merula; Tp, Turdus philomelos). Together with M. martes (gape width $>2 \mathrm{~cm}$ ), these disperser species account for $97.0 \%$ of fruit removal interactions and $98.6 \%$ of the seed rain in the Białowieża Forest, Poland. The color of horizontal lines in (A) depict the mean gape width of disperser species in (B), respectively.

with one seed per fruit. Fruit diameter correlated positively with the number of seeds per fruit only in three plant species (Figure 5): $R$. cathartica (Wald- $\chi^{2}=10.61, p=0.004$ ), $R$. nigrum (Wald $-\chi^{2}=199.97, p<0.001$ ) and R. spicatum (Wald- $\chi^{2}=75.15$, $p<0.001)$. The variation in the mean seed mass per fruit was mostly explained by the differences between species, with only small contributions by individual and subindividual differences (Table 1). The mean seed mass per fruit correlated positively with fruit diameter in five of the nine studied plant species (Figure 6): F. alnus (Wald- $\chi^{2}=57.53, p<0.001$ ), $P$. padus (Wald $\left.-\chi^{2}=14.83, p=0.001\right)$, S. nigra (Wald $\left.-\chi^{2}=7.06, p=0.071\right)$, S. aucuparia (Wald- $\chi^{2}=17.55, p=0.010$ ) and V. opulus (Wald$\left.\chi^{2}=26.63, p<0.001\right)$.

\section{Consequences of Gape-Size Limitations for Dispersed Seeds}

Tests for pair-wise differences between the main seed disperser species with respect to the number or mass of dispersed seeds per fruit showed significant differences for four of the nine plant species (Figures 5, 6). For R. nigrum, the small-gaped E. rubecula tended to disperse, on average, seeds from fruits with fewer seeds per fruit than did S. borin $(p=0.033)$ or the three main large-gaped seed dispersers M. martes, T. merula, T. philomelos $(p<0.001)$. S. atricapilla and S. borin, in turn, dispersed seeds from fruits with fewer seeds than did the three main largegaped seed dispersers (both $p \leq 0.002$, Figure 5D). The mean mass of the dispersed seeds did barely differ between the main small-gaped seed dispersers (E. rubecula, S. atricapilla, S. borin). However, in all but one comparison, E. rubecula, S. atricapilla and $S$. borin dispersed smaller seeds than the main large-gaped seed dispersers for three plant species, namely, F. alnus, S. aucuparia and $V$. opulus ( $p<0.001$ for two, $p<0.05$ for one, and $p<0.1$ for three species comparisons, respectively). Only in F. alnus, $S$. borin did not disperse seeds smaller than those dispersed by the large-gaped dispersers $(p=0.148)$, but differences between the main seed dispersers (even between the small-gaped seed dispersers) became significant $(p<0.001)$, when we strongly increased the number of samples for bootstrapping (e.g., 500 instead of 50 fruits).

\section{DISCUSSION}

The importance of within-species trait variation in structuring species interactions such as seed dispersal has long been noted (Wheelwright, 1985; Jordano, 1995b), but only recently ecologists have started to investigate the eco-evolutionary consequences 


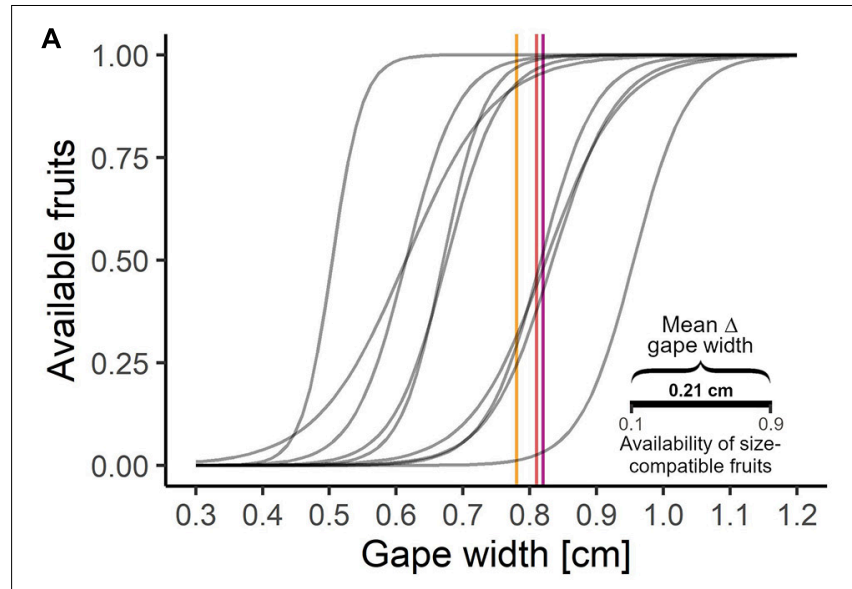

B

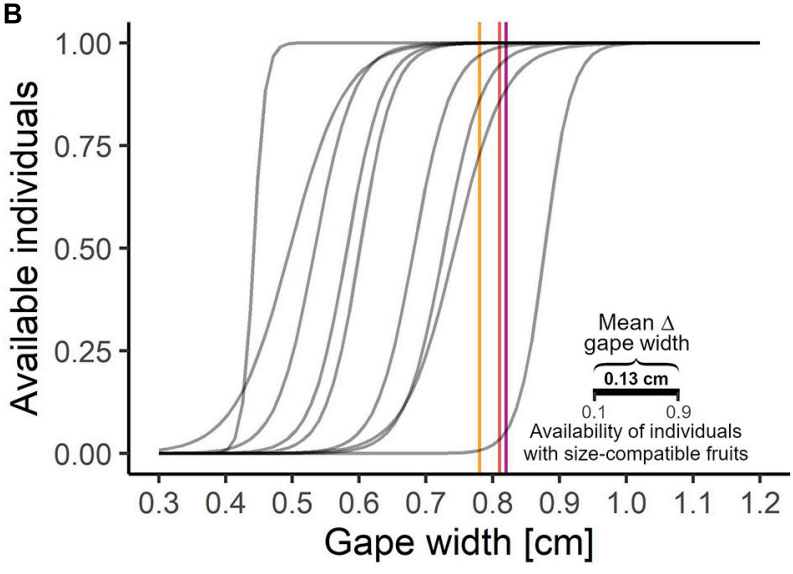

FIGURE 3 | Availability of (A) fruits or (B) individuals with size-compatible fruits as a function of the gape width of frugivorous animals. Each gray solid line displays one plant species. The black horizontal line illustrates the mean difference in the gape width of animals that allows animals to feed on either 10 or $90 \%$ of (A) fruits, or (B) plant individuals, respectively. The colored vertical lines depict the mean gape width of the small-gaped disperser $E$. rubecula $(0.78 \mathrm{~cm})$, S. atricapilla $(0.82 \mathrm{~cm})$ and $S$. borin $(0.83 \mathrm{~cm})$, respectively.

(Herrera, 2009; Bolnick et al., 2011; González-Varo and Traveset, 2016; Des Roches et al., 2018; Schupp et al., 2019; Snell et al., 2019). Our study showed that the community-wide trait variation in fruit diameter of plants and the gape width of frugivores is large among species, but also considerable within species. Every plant species produced fruits of a size that could be swallowed by the six seed disperser species previously shown to be quantitatively important for seed dispersal in this community (Albrecht et al., 2013). Only the fruits of $V$. opulus were too large to be consumed and dispersed by all main seed disperser species. However, these fruits are usually eaten several months after their appearance, when they have become smaller due to desiccation (Hernández, 2009). The dried, smaller fruits provide a food source in winter that is accessible even to small-gaped dispersers (Hernández, 2009). Consequently, mismatches in size between plants and their disperser are rare in temperate forests at the species level (González-Varo and Traveset, 2016), which might render the associated seed dispersal processes relatively robust against anthropogenic pressures (Albrecht et al., 2013, 2014; Farwig et al., 2017; Emer et al., 2019).

By contrast, at the subindividual plant level, the fruit choices of small-gaped seed dispersers were limited for the plants F. alnus, $R$. nigrum, and $S$. aucuparia, with the main small-gaped seed dispersers being able to feed only on $31-55 \%$ of the accessible fruits. Such size mismatches between dispersers and fruits may in part explain why $47-78 \%$ of the fruits in previously described populations of $F$. alnus remained undispersed (Hampe, 2008; Szewczyk et al., 2019). However, because the fruit size of each plant species varied more strongly within than between individuals, the main seed dispersers were still able to feed on the fruits of individual plants (except those of large-fruited $V$. opulus). On average, plants were able to interact with animals, whose gape width was $0.082 \mathrm{~cm}$ smaller, only due to subindividual trait variation in fruit size. These tiny differences in size could correspond to a potential increase of 0-7 disperser species $($ mean $=2.1$ ) at the level of plant individuals. Herrera (2009) found that, in terms of the total variation in fruit size, subindividual variation was larger than variation among individuals in 20 of 25 fleshy-fruited plant species. Together, these findings indicate that the large subindividual trait variation is characteristic for fleshy-fruited plant species, and allows for a broader range of interaction partners than would be expected based on the mean fruit sizes of plant species in plantfrugivore communities.

The number of disperser species did not decline with increasing fruit diameter, although species with larger gape widths preferentially fed on larger fruits. Large-gaped frugivores were usually heavier (Supplementary Information 1.2) and their feeding on energy-rich resources would maximize their energy intake (Albrecht et al., 2018a,b; Quintero et al., 2020). An increase in preferred fruit size with increasing gape width has been observed in other plant-frugivore communities as well, especially in tropical ecosystems, where at the species level there is a much larger trait variation in both fruit diameter and gape width (Wheelwright, 1985; Jordano, 1987; Lambert, 1989; Noma and Yumoto, 1997; Moran and Catterall, 2010; Burns, 2013; Chen and Moles, 2015; Dehling et al., 2016; Bender et al., 2018). Even within the same plant species, dispersers not limited by gape width were shown to preferentially feed on larger fruits (Sallabanks, 1993; Sobral et al., 2010).

In previous studies, birds were observed to peck rather than to swallow fruits that were larger than their gape (Levey, 1987; Rey et al., 1997; Hernández, 2008; Rey, 2011), but the birds were either kept under captive conditions and forced to feed on the fruits (Levey, 1987; Rey et al., 1997) or large fruits were the only food resource in the close vicinity (Hernández, 2008; Rey, 2011). In our study, there was no evidence of pecking with increasing fruit diameter, as the pecking of fruits was very rarely observed during fruit removal ( $<2 \%$ of all interactions). In addition, pecking may reflect responses other than gapesize limitations, such as difficulty in approaching less accessible fruits or exploratory probing (Supplementary Figure 3). These observations suggest that fruit pecking is not frequently used to overcome gape-size limitations, at least in most seed dispersers and as long as multiple food sources are available. A recent 

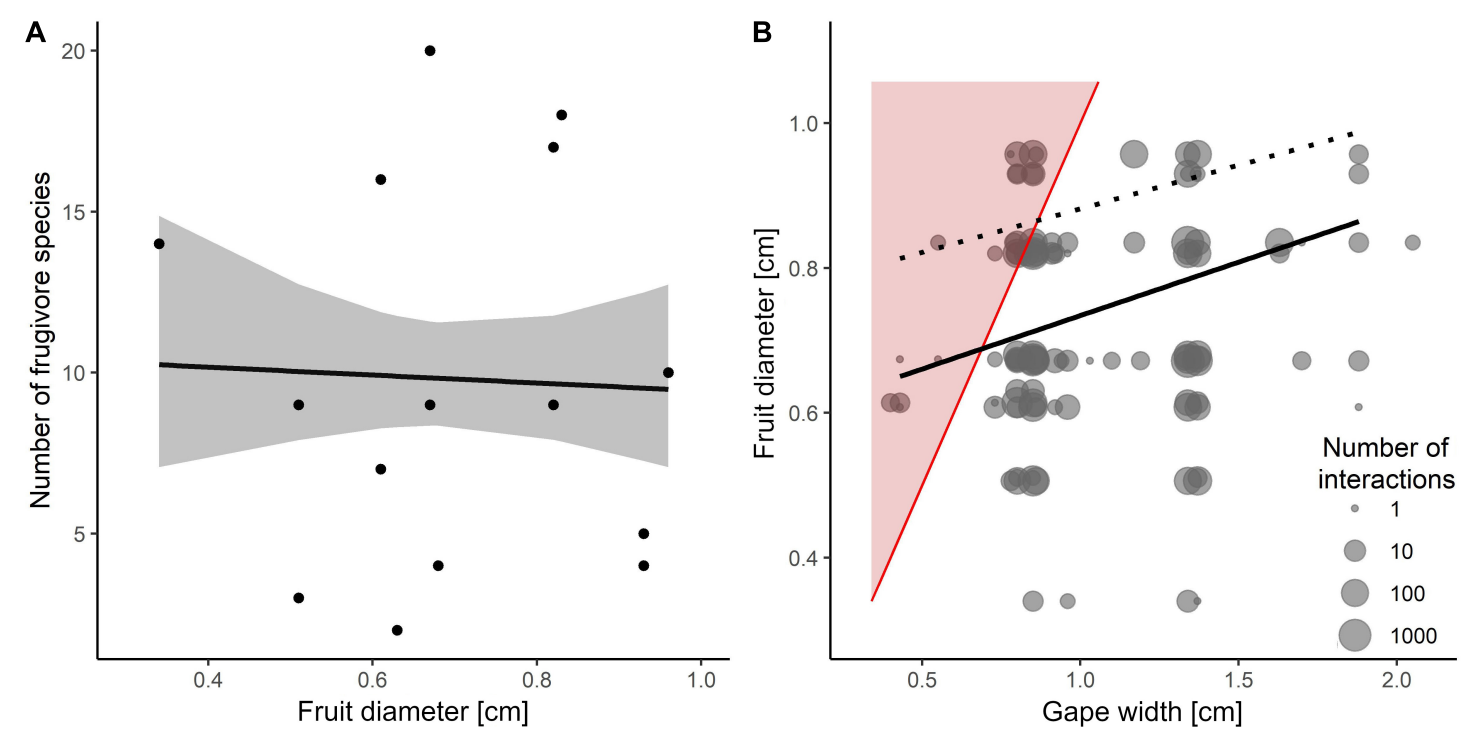

FIGURE 4 | (A) The effect of fruit diameter on the number of disperser species per plant species. The gray-shaded area indicates 95\% confidence intervals. (B) The maximum and mean diameter of fruits of plant species dispersed by animals with different gape widths during fruit removal observations (Albrecht et al., 2013; Schlautmann et al., 2021) in Białowieża Forest, Poland. The red-shaded area displays morphological "forbidden links" between plants and animals based on mean trait-values.

study likewise showed that the diet and body conditions of the small-gaped Sardinian warbler Curruca melanocephala could be primarily predicted by the local density of accessible fruits, not by the total fruit density (González-Varo et al., 2021).

The finding that no plant species only produced fruits larger than the gapes of E. rubecula, S. atricpilla, and S. borin suggests more effective seed dispersal by the six main seed dispersers than by the three large-gaped seed dispersers ( $T$. merula, T. philomelos, and M. martes) alone. For fruit plants, interactions with many seed disperser species may increase the overall quantity of dispersed seeds, the probability of plant recruitment, and therefore parental fitness (Herrera, 1984; Schupp et al., 2010). In addition, the reliance on a large diversity of seed disperser species provides a bet-hedging strategy of plant individuals to guarantee constant seed dispersal even during years when the population sizes of single disperser species are low (Herrera, 1998; Blüthgen et al., 2016). This suggests that subindividual variation in plant traits can influence the fecundity of plant species and may thus be under selection (Herrera, 2009, 2017), especially in animal-dispersed plants (Jordano, 1995b; Sobral et al., 2013, 2019). However, rather than increases or decreases in subindividual trait variation per se, natural selection might affect the variation in fruit diameter among plant individuals to promote interactions with key seed dispersers.

Our study showed that fruit diameter correlated positively with the number or the mean mass of seeds in eight of the nine studied plant species. This suggests that a positive relationship between fruit diameter and seed traits is common in fleshyfruited plants, in line with the findings of many single-species studies (e.g., Herrera, 1988; Sallabanks, 1993; Herrera et al., 1994; Jordano, 1995b; Alcántara and Rey, 2003; Hernández, 2009; Rodríguez-Pérez and Traveset, 2010; González-Castro et al.,
2019; Traveset et al., 2019; Carvalho et al., 2021). Potential mismatches between gapes and fruits can, therefore, decrease the mass and the number of dispersed seeds in small-gaped dispersers, as this was shown for four of the nine studied plant species. Even small differences in the gape width among species, such as those between E. rubecula (gape width $=0.78 \mathrm{~cm}$ ) and $S$. atricapilla $(0.82 \mathrm{~cm})$ or $S$. borin $(0.83 \mathrm{~cm})$, might be large enough to induce selective pressures on fruits traits on the long-term.

A similar pattern was found in an in-situ study conducted in the Mediterranean areas, where for Olea europea the fruit choice by dispersers was limited by their gape size (Rey et al., 1997). The positive correlation between fruit size and seed size (Alcántara and Rey, 2003) also explains the smaller seeds dispersed by $S$. atricapilla than by large-gaped T. philomelos (González-Varo et al., 2014). For the spurge olive Cneuorum tricoccon, larger seeds were found in the scat of $M$. martes than in that of small-gaped lizards (Traveset et al., 2019). Even in aggregated fruits such as Rubus spp., avian frugivores may select for seeds of different sizes by selecting fruits of different sizes (e.g., Jordano, 1984b). Seed size can, in turn, affect the post-dispersal regeneration of plants. Larger seeds are usually less susceptible to soil pathogens and produce larger seedlings, especially in adverse environments, but they may also be poorly dispersed (Murray et al., 1993; Leishman et al., 2000; Fricke et al., 2019; González-Castro et al., 2019). This suggests that gape-size limitations play a pivotal role in seed dispersal and influence the effectiveness of seed disperser species by constraining the efficiency of fruit handling (Schupp et al., 2010), even in small-fruited plants. This mechanism provides an explanation how the co-evolution of large seeds and animal seed dispersal started from small seeds 80 million years ago 

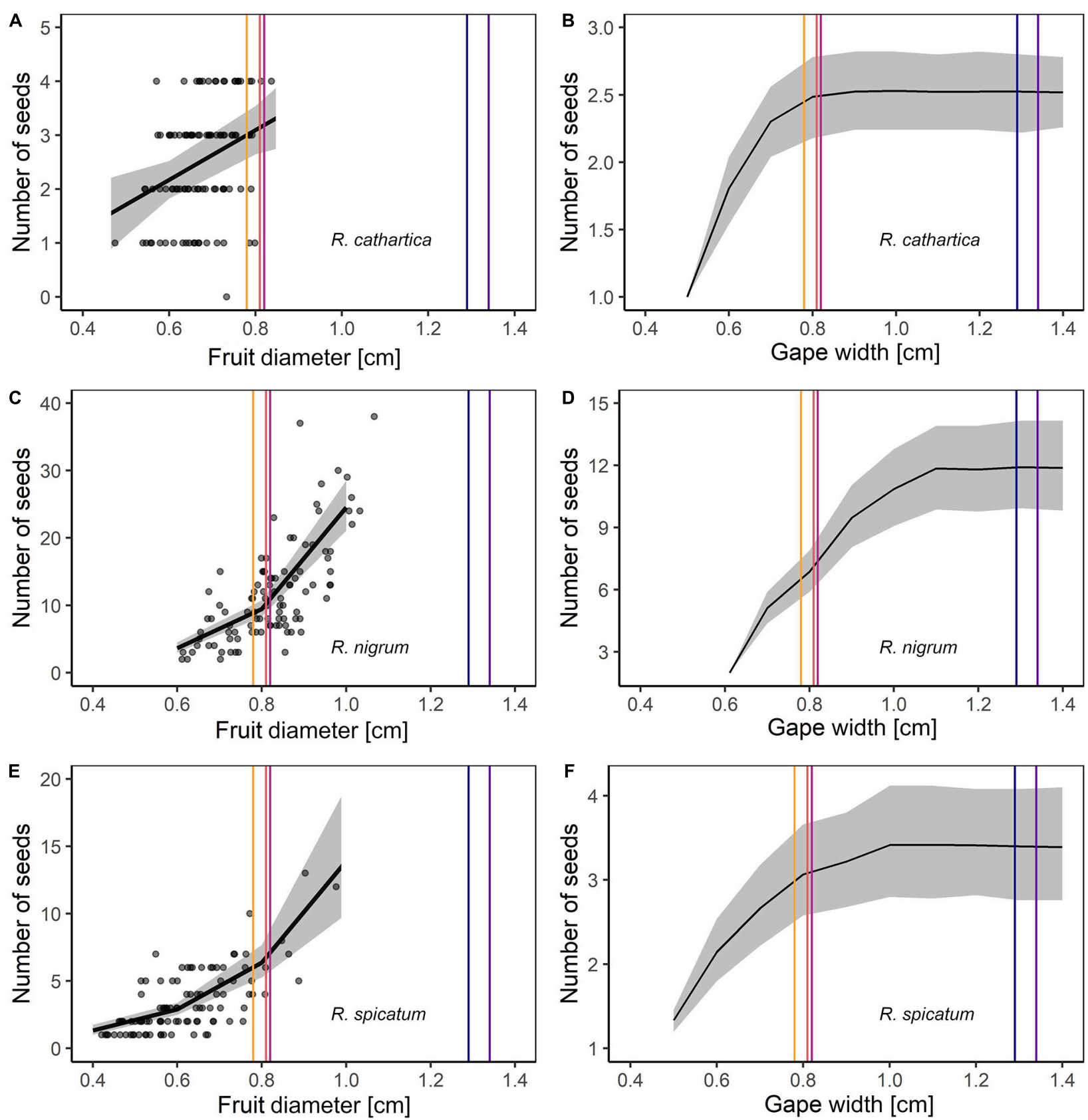

FIGURE 5 | (A,C,E) The number of seeds per fruit in relation to fruit diameter and (B,D,F) the predicted number of seeds per fruit taken up by animals depending on their gape width in Rhamnus cathartica (A,B), Ribes nigrum (C,D) and Ribes spicatum (E,F). The number of seeds per fruit was not related to the diameter of fruits in the other study species in Białowieża Forest, Poland. Shaded areas indicate the $95 \%$ confidence intervals. The colored vertical lines display the mean gape width of the most important animal dispersers of the plant species (but M. martes with a gape width $>2 \mathrm{~cm}$ ). Please see Figure 2 for more information.

(Eriksson, 2016). However, as the effect of seed size on plant performance during and after seed dispersal may differ between plant species and disperser species, the effects of gape-size limitations on the efficiency of seed dispersal may not always be straightforward (Fricke et al., 2019; Schupp et al., 2019). The consequences of the patterns identified in this work may be a promising avenue for future research (e.g., Fricke et al., 2019; Carvalho et al., 2021).

\section{CONCLUSION}

Comparisons of community-wide patterns of the sizes of fruits and gapes in a temperate plantfrugivore association revealed that, even for small fruits $(<1 \mathrm{~cm}$ diameter), gape-size limitations affect fruit removal and seed dispersal interactions, mostly at the subindividual level and only rarely at the plant species 


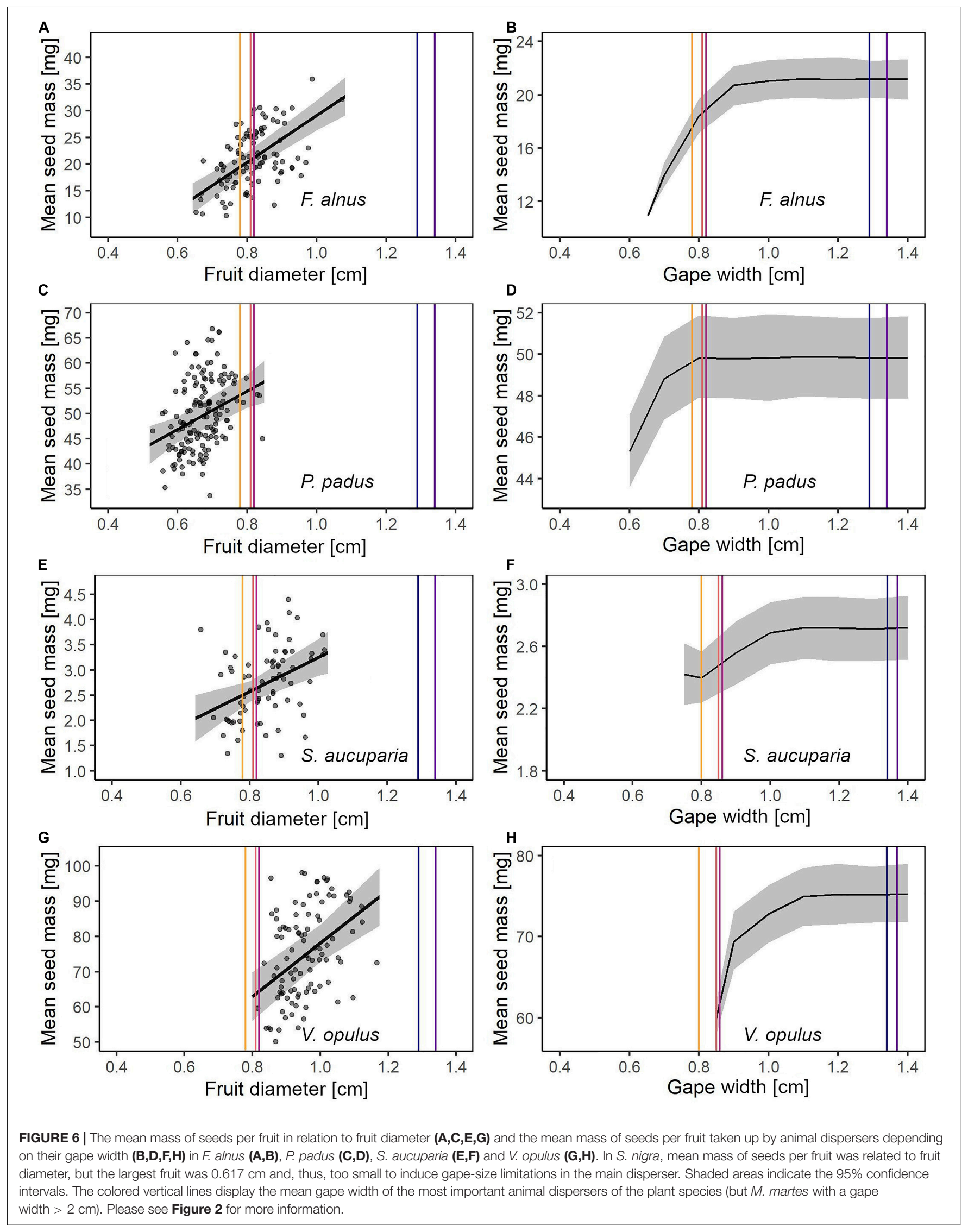


level. The large subindividual trait variation in fruit size ensures a high connectedness of the small-fruited plants with smallgaped animal dispersers, and possibly makes fruit removal of these plants tolerant to the loss of frugivores. Simultaneously, however, positive fruit-seed trait relationships are common in fleshy-fruited plants species, such that gape-size limitations lead to altered dispersal pattern in the number or size of seeds, when only the large-gaped dispersers become extinct. This study highlights the importance of the different levels of trait variation and gape-size limitation in plant-frugivore communities for structuring species interactions and the co-evolution of seed size and animal seed dispersal.

\section{DATA AVAILABILITY STATEMENT}

The original contributions presented in the study are included in the article/Supplementary Material, or are available online from Dryad Digital Repository https://doi.org/10.5061/dryad. 0vt4b8gzk (Rehling et al., 2021).

\section{ETHICS STATEMENT}

Ethical review and approval was not required for the animal study because this study relied on previously published data and indirect methods for assessing the behavior of animals.

\section{AUTHOR CONTRIBUTIONS}

FR, NF, and DS conceived and designed the experiments. FR and LB collected and measured fruits and seeds, and performed a pilot germination study. BJ administrated field work. JA

\section{REFERENCES}

Albrecht, J., Berens, D. G., Blüthgen, N., Jaroszewicz, B., Selva, N., and Farwig, N. (2013). Logging and forest edges reduce redundancy in plant-frugivore networks in an old-growth European forest. J. Ecol. 101, 990-999. doi: 10.1111/ 1365-2745.12105

Albrecht, J., Bohle, V., Berens, D. G., Jaroszewicz, B., Selva, N., and Farwig, N. (2015). Variation in neighbourhood context shapes frugivore-mediated facilitation and competition among co-dispersed plant species. J. Ecol. 103, 526-536. doi: 10.1111/1365-2745.12375

Albrecht, J., Classen, A., Vollstädt, M. G. R., Mayr, A., Mollel, N. P., Schellenberger Costa, D., et al. (2018a). Plant and animal functional diversity drive mutualistic network assembly across an elevational gradient. Nat. Commun. 9:3177. doi: 10.1038/s41467-018-05610-w

Albrecht, J., Gertrud Berens, D., Jaroszewicz, B., Selva, N., Brandl, R., and Farwig, N. (2014). Correlated loss of ecosystem services in coupled mutualistic networks. Nat. Commun. 5:3810. doi: 10.1038/ncomms4810

Albrecht, J., Hagge, J., Schabo, D. G., Schaefer, H. M., and Farwig, N. (2018b). Reward regulation in plant-frugivore networks requires only weak cues. Nat. Commun. 9:4838. doi: 10.1038/s41467-018-07362-z

Alcántara, J. M., and Rey, P. J. (2003). Conflicting selection pressures on seed size: evolutionary ecology of fruit size in a bird-dispersed tree, Olea europaea. J. Evol. Biol. 16, 1168-1176. doi: 10.1046/j.1420-9101.2003.00618.x

Bates, D., Mächler, M., Bolker, B., and Walker, S. (2015). Fitting linear mixed-effects models using lme4. J. Stat. Softw. 67, 1-48. doi: 10.18637/jss.v067.i01 and JS provided data on species interactions in Białowieża Forest. PJ provided data on within-species variation in gape widths of the main seed dispersers. FR analyzed the data and wrote the first draft of the manuscript. All authors contributed substantially to revisions thereafter and gave final approval for publication.

\section{FUNDING}

This project was funded by the German Research Foundation (FA925/10-1, 10-2; BE 6041/1-1, SCHA 2085/1-2).

\section{ACKNOWLEDGMENTS}

We greatly thank the administration of the Białowieża National Park, the forest administrations of Białowieża, Hajnówka and Browsk, and Polish authorities [Ministry of Environment, GDOS (Polish General Directorate of Environment Conservation, Warsaw) and RDOS (Regional Directorate of Environment Conservation, Białystok)] for the permission to research in Białowieża Forest. The research was conducted in cooperation with the International Centre for Research on Forest Ecosystems of the University of Warsaw. We thank the two reviewers DL and $\mathrm{MO}$ for their constructive comments on earlier versions of the manuscript.

\section{SUPPLEMENTARY MATERIAL}

The Supplementary Material for this article can be found online at: https://www.frontiersin.org/articles/10.3389/fevo.2021. 698885/full\#supplementary-material

Bender, I. M. A., Kissling, W. D., Blendinger, P. G., Böhning-Gaese, K., Hensen, I., Kühn, I., et al. (2018). Morphological trait matching shapes plant-frugivore networks across the Andes. Ecography (Cop.). 41, 1910-1919. doi: 10.1111/ecog. 03396

Blüthgen, N., Menzel, F., Hovestadt, T., Fiala, B., and Blüthgen, N. (2007). Specialization, constraints, and conflicting interests in mutualistic networks. Curr. Biol. 17, 341-346. doi: 10.1016/j.cub.2006.12.039

Blüthgen, N., Simons, N. K., Jung, K., Prati, D., Renner, S. C., Boch, S., et al. (2016). Land use imperils plant and animal community stability through changes in asynchrony rather than diversity. Nat. Commun. 7:10697. doi: 10.1038/ ncomms10697

Bolnick, D. I., Amarasekare, P., Araújo, M. S., Bürger, R., Levine, J. M., Novak, M., et al. (2011). Why intraspecific trait variation matters in community ecology. Trends Ecol. Evol. 26, 183-192. doi: 10.1016/j.tree.2011. 01.009

Brodie, J. F. (2017). Evolutionary cascades induced by large frugivores. Proc. Natl. Acad. Sci. U.S.A. 114, 11998-12002. doi: 10.1073/pnas.1710172114

Brodie, J. F., Helmy, O. E., Brockelman, W. Y., and Maron, J. L. (2009). Bushmeat poaching reduces the seed dispersal and population growth rate of a mammaldispersed tree. Ecol. Appl. 19, 854-863. doi: 10.1890/08-0955.1

Burns, K. C. (2013). What causes size coupling in fruit-frugivore interaction webs? Ecology 94, 295-300.

Carvalho, C., da, S., Lucas, M. S., and Côrtes, M. C. (2021). Rescuing intraspecific variation in human-impacted environments. J. Appl. Ecol. 58, 350-359. doi: $10.1111 / 1365-2664.13764$ 
Case, S. B., and Tarwater, C. E. (2020). Functional traits of avian frugivores have shifted following species extinction and introduction in the Hawaiian Islands. Funct. Ecol. 34, 2467-2476. doi: 10.1111/1365-2435. 13670

Chen, S. C., and Moles, A. T. (2015). A mammoth mouthful? A test of the idea that larger animals ingest larger seeds. Glob. Ecol. Biogeogr. 24, 1269-1280. doi: 10.1111/geb. 12346

Correa, S. B., Araujo, J. K., Penha, J. M. F., da Cunha, C. N., Stevenson, P. R., and Anderson, J. T. (2015). Overfishing disrupts an ancient mutualism between frugivorous fishes and plants in Neotropical wetlands. Biol. Conserv. 191, 159-167. doi: 10.1016/j.biocon.2015.06.019

Dehling, D. M., Jordano, P., Schaefer, H. M., Böhning-Gaese, K., and Schleuning, M. (2016). Morphology predicts species' functional roles and their degree of specialization in plant-Frugivore interactions. Proc. R. Soc. B Biol. Sci. 283:20152444. doi: 10.1098/rspb.2015.2444

Des Roches, S., Post, D. M., Turley, N. E., Bailey, J. K., Hendry, A. P., Kinnison, M. T., et al. (2018). The ecological importance of intraspecific variation. Nat. Ecol. Evol. 2, 57-64. doi: 10.1038/s41559-017-0402-5

Dogterom, M. H., Winston, M. L., and Mukai, A. (2000). Effect of pollen load size and source (self, outcross) on seed and fruit production in highbush blueberry cv. "Bluecrop" (Vaccinium corymbosum; Ericaceae). Am. J. Bot. 87, 1584-1591. doi: $10.2307 / 2656734$

Eklöf, A., Jacob, U., Kopp, J., Bosch, J., Castro-Urgal, R., Chacoff, N. P., et al. (2013). The dimensionality of ecological networks. Ecol. Lett. 16, 577-583. doi: 10.1111/ele.12081

Emer, C., Galetti, M., Pizo, M. A., Jordano, P., and Verdú, M. (2019). Defaunation precipitates the extinction of evolutionarily distinct interactions in the Anthropocene. Sci. Adv. 5:eaav6699. doi: 10.1126/sciadv.aav6699

Eriksson, O. (2016). Evolution of angiosperm seed disperser mutualisms: the timing of origins and their consequences for coevolutionary interactions between angiosperms and frugivores. Biol. Rev. 91, 168-186. doi: 10.1111/brv. 12164

Farwig, N., Schabo, D. G., and Albrecht, J. (2017). Trait-associated loss of frugivores in fragmented forest does not affect seed removal rates. J. Ecol. 105, 20-28. doi: 10.1111/1365-2745.12669

Foster, M. S. (1990). Factors influencing bird foraging preferences among conspecific fruit trees. Condor 92:844. doi: 10.2307/1368720

Fox, J., and Weisberg, S. (2019). car-an R Companion to Applied Regression, 3rd Edn. Thousand Oaks CA: Sage.

Fricke, E. C., Tewksbury, J. J., and Rogers, H. S. (2019). Linking intra-specific trait variation and plant function: seed size mediates performance tradeoffs within species. Oikos 128, 1716-1725. doi: 10.1111/oik.06494

Galetti, M., Guevara, R., Côrtes, M. C., Fadini, R., Von Matter, S., Leite, A. B., et al. (2013). Functional extinction of birds drives rapid evolutionary changes in seed size. Science 340, 1086-1090. doi: 10.1126/science. 1233774

Gautier-Hion, A., Duplantier, J. M., Quris, R., Feer, F., Sourd, C., Decoux, J. P., et al. (1985). Fruit characters as a basis of fruit choice and seed dispersal in a tropical forest vertebrate community. Oecologia 65, 324-337. doi: 10.1007/BF0037 8906

González-Castro, A., Pérez-Pérez, D., Romero, J., and Nogales, M. (2019). Unraveling the seed dispersal system of an insular "ghost" dragon tree (Dracaena draco) in the wild. Front. Ecol. Evol. 7:39. doi: 10.3389/fevo.2019. 00039

González-Varo, J. P., Arroyo, J. M., and Jordano, P. (2014). Who dispersed the seeds? The use of DNA barcoding in frugivory and seed dispersal studies. Methods Ecol. Evol. 5, 806-814. doi: 10.1111/2041-210X.12212

González-Varo, J. P., and Traveset, A. (2016). The labile limits of forbidden interactions. Trends Ecol. Evol. 31, 700-710. doi: 10.1016/j.tree.2016.06.009

González-Varo, J. P., Onrubia, A., Pérez-Méndez, N., Tarifa, R., and Illera, J. C. (2021). Fruit abundance and trait matching determine diet type and body condition across frugivorous bird populations. Oikos 1-13. doi: 10.1111/oik. 08106

Guimarães, P. R., Galetti, M., and Jordano, P. (2008). Seed dispersal anachronisms: rethinking the fruits extinct megafauna ate. PLoS One 3:e1745. doi: 10.1371/ journal.pone.0001745

Hampe, A. (2008). Fruit tracking, frugivore satiation, and their consequences for seed dispersal. Oecologia 156, 137-145. doi: 10.1007/s00442-008-0979-0
Herrera, C. M. (1988). The fruiting ecology of Osyris quadripartita: individual variation and evolutionary potential. Ecology 69, 233-249. doi: 10.2307/1943179

Hernández, Á (2008). Cherry removal by seed-dispersing mammals: mutualism through commensal association with frugivorous birds. Polish J. Ecol. 56, 127-138.

Hernández, Á (2009). Birds and guelder rose Viburnum opulus: selective consumption and dispersal via regurgitation of small-sized fruits and seeds. Plant Ecol. 203, 111-122. doi: 10.1007/sll258-008-9514-y

Herrera, C. M. (1984). Adaptation to frugivory of Mediterranean avian seed dispersers. Ecology 65, 609-617.

Herrera, C. M. (1998). Long-term dynamics of Mediterranean frugivorous birds and fleshy fruits: a 12-year study. Ecol. Monogr. 68, 511-538.

Herrera, C. M. (2009). Multiplicity in Unity: Plant Subindividual Variation in Interactions with Animals. Chicago: University of Chicago Press.

Herrera, C. M. (2017). The ecology of subindividual variability in plants: patterns, processes, and prospects. Web Ecol. 17, 51-64. doi: 10.5194/we-17-51-2017

Herrera, C. M., Jordano, P., Lopez-Suria, L., and Amat, J. A. (1994). Recruitment of a mast-fruiting, bird-dispersed tree: bridging frugivore activity and seedling establishment. Ecol. Monogr. 64, 315-344.

Howe, F., and Smallwood, J. (1982). Ecology of seed dispersal. Annu. Rev. Ecol. Syst. 13, 201-228. doi: 10.1146/annurev.es.13.110182.001221

Jackson, J. E., and Sharples, R. O. (1971). The influence of shade and withintree position on apple fruit size, colour and storage quality. J. Hortic. Sci. 46, 277-287. doi: 10.1080/00221589.1971.11514408

Janzen, D. H., and Martin, P. S. (1982). Neotropical anachronisms: the fruits the gomphotheres ate. Science 215, 19-27. doi: 10.1126/science.215.4528.19

Jaroszewicz, B., Cholewiñska, O., Gutowski, J. M., Samojlik, T., Zimny, M., and Latałowa, M. (2019). Białowieza forest-a relic of the high naturalness of European forests. Forests 10:849. doi: 10.3390/f101 00849

Jaroszewicz, B., Piroznikow, E., and Sondej, I. (2013). Endozoochory by the guild of ungulates in Europe's primeval forest. For. Ecol. Manage. 305, 21-28. doi: 10.1016/j.foreco.2013.05.004

Jordano, P. (1984a). Relaciones Entre Plantas y Aves Frugivoras en el Matorral Mediterráneo del Área de Doñana. Ph.D thesis. Sevilla: University of Sevilla.

Jordano, P. (1984b). Seed weight variation and differential avian dispersal in blackberries Rubus ulmifolius. Oikos 43, 149-153.

Jordano, P. (1987). Frugivory, external morphology and digestive system in Mediterranean sylviid warblers Sylvia spp. Ibis (Lond. 1859) 129, 175-189. doi: 10.1111/j.1474-919X.1987.tb03199.x

Jordano, P. (1995a). Angiosperm fleshy fruits and seed dispersers: a comparative analysis of adaptation and constraints in plant-animal interactions. Am. Nat. $145,163-191$.

Jordano, P. (1995b). Frugivore-mediated selection on fruit and seed size: birds and St. Lucie's cherry, Prunus mahaleb. Ecology 76, 2627-2639.

Jordano, P. (2014). "Fruits and frugivory," in Seeds: the Ecology of Regeneration in Plant Communities, ed. R. S. Gallagher (Wallingford: CABI), 18-61. doi: $10.1079 / 9781780641836.0018$

Kurten, E. L. (2013). Cascading effects of contemporaneous defaunation on tropical forest communities. Biol. Conserv. 163, 22-32. doi: 10.1016/j.biocon.2013. 04.025

Lambert, F. (1989). Fig-eating by birds in a Malaysian lowland rain forest. J. Trop. Ecol. 5, 401-412.

Leishman, M. R., Wright, I. J., Moles, A. T., and Westoby, M. (2000). "The evolutionary ecology of seed size," in Seeds: the Ecology of Regeneration in Plant Communities, ed. CASBI Publishing (Wallingford, CT: CABI), 31-57. doi: 10.1079/9780851994321.0031

Levey, D. J. (1987). Seed size and fruit-handling techniques of avian frugivores. Am. Nat. 129, 471-485. doi: 10.1086/284652

Lim, J. Y., Svenning, J.-C., Göldel, B., Faurby, S., and Kissling, W. D. (2020). Frugivore-fruit size relationships between palms and mammals reveal past and future defaunation impacts. Nat. Commun. 11:4904. doi: 10.1038/s41467-02018530-5

Lloyd, D. G. (1984). Variation strategies of plants in heterogeneous environments. Biol. J. Linn. Soc. 21, 357-385. doi: 10.1111/j.1095-8312.1984.tb01600.x

Manzur, M. I., and Courtney, S. P. (1984). Influence of insect damage in fruits of hawthorn on bird foraging and seed dispersal. Oikos 43, 265-270. doi: 10.2307/ 3544142 
Mikusiński, G., Bubnicki, J. W., Churski, M., Czeszczewik, D., Walankiewicz, W., and Kuijper, D. P. J. (2018). Is the impact of loggings in the last primeval lowland forest in Europe underestimated? The conservation issues of Białowieża Forest. Biol. Conserv. 227, 266-274. doi: 10.1016/j.biocon.2018. 09.001

Moermond, T. C., and Denslow, J. S. (1985). Neotropical avian frugivores: patterns of behavior, morphology, and nutrition, with consequences for fruit selection. Ornithol. Monogr. 36, 865-897.

Moran, C., and Catterall, C. P. (2010). Can functional traits predict ecological interactions? A case study using rain forest frugivores and plants in Australia. Biotropica 42, 318-326. doi: 10.1111/j.1744-7429.2009.00 594.x

Muller-Landau, H. C. (2010). The tolerance-fecundity trade-off and the maintenance of diversity in seed size. Proc. Natl. Acad. Sci. U. S. A. 107, 4242-4247. doi: 10.1073/pnas.0911637107

Murray, K. G., Winnett-Murray, K., Cromie, E. A., Minor, M., and Meyers, E. (1993). The influence of seed packaging and fruit color on feeding preferences of American robins. Vegetatio 107/108, 217-226. doi: 10.1007/BF0005 2224

Noma, N., and Yumoto, T. (1997). Fruiting phenology of animal-dispersed plants in response to winter migration of frugivores in a warm temperate forest on Yakushima Island, Japan. Ecol. Res. 12, 119-129. doi: 10.1007/BF0252 3777

Pérez-Méndez, N., Jordano, P., García, C., and Valido, A. (2016). The signatures of Anthropocene defaunation: cascading effects of the seed dispersal collapse. Sci. Rep. 6:24820. doi: 10.1038/srep24820

Quinn, G. P., and Keough, M. J. (2002). Experimental Design and Data Analysis for Biologists. Cambridge: Cambridge University Press. doi: 10.1017/ CBO9780511806384

Quintero, E., Pizo, M. A., and Jordano, P. (2020). Fruit resource provisioning for avian frugivores: the overlooked side of effectiveness in seed dispersal mutualisms. J. Ecol. 108, 1358-1372. doi: 10.1111/1365-2745. 13352

R Core Team (2020). R: a Language and Environment for Statistical Computing. Vienna: The R Project for Statistical Computing.

Rehling, F., Jaroszewicz, B., Braasch, L., Albrecht, J., Jordano, P., Schlautmann, J., et al. (2021). Data from: within-species trait variation can lead to size limitations in seed dispersal of small-fruited plants. Dryad Dataset. doi: 10.5061/dryad. 0vt4b8gzk

Rey, P. J. (2011). Preserving frugivorous birds in agro-ecosystems: lessons from Spanish olive orchards. J. Appl. Ecol. 48, 228-237. doi: 10.1111/j.1365-2664. 2010.01902.x

Rey, P. J., Gutiérrez, J. E., Alcántara, J., and Valera, F. (1997). Fruit size in wild olives: implications for avian seed dispersal. Funct. Ecol. 11, 611-618. doi: $10.1046 / j .1365-2435.1997 .00132 . x$

Robbins, J., and Moore, P. P. (1991). Fruit morphology and fruit strength in a seedling population of Red Raspberry. HortScience 26, 294-295. doi: 10.21273/ HORTSCI.26.3.294

Rodríguez-Pérez, J., and Traveset, A. (2010). Seed dispersal effectiveness in a plant-lizard interaction and its consequences for plant regeneration after disperser loss. Plant Ecol. 207, 269-280. doi: 10.1007/11258-0099671-7

Sallabanks, R. (1993). Hierarchical mechanisms of fruit selection by an Avian frugivore. Ecology 74, 1326-1336.

Samojlik, T., Fedotova, A., Niechoda, T., and Rotherham, I. D. (2019). Culturally modified trees or wasted timber: different approaches to marked trees in Poland's Białowieża Forest. PLoS One 14:e0211025. doi: 10.1371/JOURNAL. PONE.0211025

Schlautmann, J., Rehling, F., Albrecht, J., Jaroszewicz, B., Schabo, D. G., and Farwig, N. (2021). Observing frugivores or collecting scats: a method comparison to construct quantitative seed dispersal networks. Oikos 130, 1359-1369. doi: 10. 1111/oik.08175

Schleuning, M., Neuschulz, E. L., Albrecht, J., Bender, I. M. A., Bowler, D. E., Dehling, D. M., et al. (2020). Trait-based assessments of climate-change impacts on interacting species. Trends Ecol. Evol. 35, 319-328. doi: 10.1016/j.tree.2019. 12.010
Schuetzenmeister, A., and Dufey, F. (2020). VCA: Variance Component Analysis. Available online at: https://cran.r-project.org/package=VCA. (Accessed June 17, 2020).

Schupp, E. W., Jordano, P., and Gómez, J. M. (2010). Seed dispersal effectiveness revisited: a conceptual review. New Phytol. 188, 333-353. doi: 10.1111/j.14698137.2010.03402.x

Schupp, E. W., Zwolak, R., Jones, L. R., Snell, R. S., Beckman, N. G., Aslan, C., et al. (2019). Intrinsic and extrinsic drivers of intraspecific variation in seed dispersal are diverse and pervasive. AoB Plants 11:plz067. doi: 10.1093/aobpla/plz067

Searle, S. R., Casella, G., and McCulloch, C. E. (1992). Variance Components. New York, NY: J.W. Wiley.

Snell, R. S., Beckman, N. G., Fricke, E., Loiselle, B. A., Carvalho, C. S., Jones, L. R., et al. (2019). Consequences of intraspecific variation in seed dispersal for plant demography, communities, evolution and global change. AoB Plants 11:plz016. doi: 10.1093/aobpla/plz016

Snow, B., and Snow, D. (1988). Birds and Berries: a Study of an Ecological Interaction. Calton: Poyser, doi: 10.5040/9781472597076

Sobral, M., Guitián, J., Guitián, P., and Larrinaga, A. R. (2013). Selective pressure along a latitudinal gradient affects subindividual variation in plants. PLoS One 8:e74356. doi: 10.1371/journal.pone.0074356

Sobral, M., Guitián, J., Guitián, P., Violle, C., and Larrinaga, A. R. (2019). Exploring sub-individual variability: role of ontogeny, abiotic environment and seeddispersing birds. Plant Biol. 21, 688-694. doi: 10.1111/plb.12949

Sobral, M., Larrinaga, A. R., and Guitián, J. (2010). Fruit-size preferences in wild and naive Eurasian blackbirds (Turdus merula) feeding on Oneseed Hawthorn (Crataegus monogyna). Auk 127, 532-539. doi: 10.1525/auk.2010.09079

Szewczyk, T. M., Lee, T., Ducey, M. J., Aiello-Lammens, M. E., Bibaud, H., and Allen, J. M. (2019). Local management in a regional context: simulations with process-based species distribution models. Ecol. Modell. 413:108827. doi: 10. 1016/j.ecolmodel.2019.108827

Terborgh, J., Nuñez-Iturri, G., Pitman, N. C. A., Valverde, F. H. C., Alvarez, P., Swamy, V., et al. (2008). Tree recruitment in an empty forest. Ecology 89, 1757-1768. doi: 10.1890/07-0479.1

Traveset, A., Escribano-Avila, G., Gómez, J. M., and Valido, A. (2019). Conflicting selection on Cneorum tricoccon (Rutaceae) seed size caused by native and alien seed dispersers. Evolution (N. Y.) 73, 2204-2215. doi: 10.1111/evo.13852

Wenny, D. G., Şekercioğlu, ÇH., Cordeiro, N. J., Rogers, H. S., and Kelly, D. (2016). "Seed dispersal by fruit-eating birds," in Why Birds Matter: Avian Ecological Function and Ecosystem Services, eds C. H. Sekercioglu, D. G. Wenny, and C. J. Whelan (Chicago: The University of Chicago Press), 107-146.

Wheelwright, N. T. (1985). Fruit-size, gape width, and the diets of fruit-eating birds. Ecology 66, 808-818.

Wheelwright, N. T. (1993). Fruit size in a tropical tree species: variation, preference by birds, and heritability. Vegetatio 107, 163-174. doi: 10.1007/BF00052219

Zamora, R. (2000). Functional equivalence in plant-animal interactions: ecological and evolutionary consequences. Oikos 88, 442-447.

Zwolak, R. (2018). How intraspecific variation in seed-dispersing animals matters for plants. Biol. Rev. 93, 897-913. doi: 10.1111/brv.12377

Conflict of Interest: The authors declare that the research was conducted in the absence of any commercial or financial relationships that could be construed as a potential conflict of interest.

Publisher's Note: All claims expressed in this article are solely those of the authors and do not necessarily represent those of their affiliated organizations, or those of the publisher, the editors and the reviewers. Any product that may be evaluated in this article, or claim that may be made by its manufacturer, is not guaranteed or endorsed by the publisher.

Copyright $\odot 2021$ Rehling, Jaroszewicz, Braasch, Albrecht, Jordano, Schlautmann, Farwig and Schabo. This is an open-access article distributed under the terms of the Creative Commons Attribution License (CC BY). The use, distribution or reproduction in other forums is permitted, provided the original author(s) and the copyright owner(s) are credited and that the original publication in this journal is cited, in accordance with accepted academic practice. No use, distribution or reproduction is permitted which does not comply with these terms. 